\title{
Corcheas insurgentes: usos y funciones de la música de las FARC-EP durante el conflicto armado en Colombia
}

\author{
Insurgent quavers: uses and functions of FARC-EP music during the armed conflict \\ in Colombia
}

Rafael Quishpe*

Resumen: Este artículo analiza los usos y funciones que tuvo la música producida por las FARC-EP para la organización y su trabajo político-militar durante el conflicto armado en Colombia. A partir de la revisión de fuentes primarias y secundarias, observación participante en 5 conciertos farianos y 14 entrevistas, se afirma que la música fariana -como sonido y práctica- cumplió un papel fundamental para afianzar la cohesión social e ideológica de las FARC-EP, para motivar e inspirar a sus miembros y para sostener una identidad colectiva tanto en el campo como en las ciudades. Respecto al trabajo político de la insurgencia con la sociedad civil, la música se usó para amenizar, generar simpatías y sumar solidaridades.

Palabras clave: FARC-EP, música, conflicto armado, Colombia, moral, identidad, cohesión.

\begin{abstract}
This article analyzes the uses and functions that the music produced by the FARC-EP had for the organization and its political-military work during the armed conflict in Colombia. Based on the review of primary and secondary sources, participant observation in 6 "fariano concerts" and 14 interviews, it is affirmed that Fariano music -as sound and practice- fulfilled fundamental role to strengthen the social and ideological cohesion of the FARC-EP, to motivate and inspire its members and to sustain a collective identity both in the countryside and in the cities. Regarding the political work of the insurgency with civil society, music was used to entertain, generate sympathy and add solidarity.
\end{abstract}

Keywords: FARC-EP, music, armed conflict, Colombia, motivation, identity, cohesion.

Recibido: 31 enero 2019 Aceptado: 18 marzo 2019

\footnotetext{
* Colombiano. Magíster en Construcción de Paz (Universidad de los Andes). Docente e investigador de la Universidad del Rosario (Facultad de Jurisprudencia, Grupo de Derechos Humanos). Correo electrónico: rafael.quishpe@,urosario.edu.co. Agradezco los comentarios de Ingrid Bolívar, Enzo Nussio y Amy Ritterbusch a versiones previas de este manuscrito.
} 
'Es un despertador. La canción anima, la canción concientiza, la canción organiza, la canción recluta’

Julián Conrado (músico de las FARC-EP)

\section{Introducción}

Durante los conflictos armados los combatientes en ocasiones crean, producen y circulan material musical. Ya sea para consumo interno o como parte de una estrategia más amplia hacia la sociedad civil o sus adversarios, lo cierto es que el sonido ha sido un elemento importante para el desarrollo de las organizaciones armadas y su trabajo político-militar. Pese a esto, la comprensión del papel de la música en el desarrollo de la violencia sigue siendo limitada. En América Latina (y aparte de los casos de Chile, El Salvador, Nicaragua y México1) el amplio material sonoro producido por las insurgencias -o relacionado con las mismas- es todavía hoy un campo por desarrollar para los académicos interesados en comprender a profundidad las dinámicas culturales y comunicacionales de las guerras civiles del continente ${ }^{2}$.

En Colombia, con más de 500 canciones, por lo menos 10 artistas reconocidos y la incursión en diversos géneros -desde vallenato hasta rap-, las Fuerzas Armadas Revolucionarias de Colombia-Ejército del Pueblo (FARC-EP) produjeron durante el largo conflicto armado un acumulado importante de material musical, aún poco investigado y valorado por quienes estudian la violencia e historia política del país. Por lo tanto, aún se desconocen los usos y funciones que tuvo esta música para la organización y su trabajo político-militar durante más de 60 años de confrontación armada.

En este sentido se encamina el presente artículo, el cual busca responder a la siguiente pregunta: ¿Cuál fue el rol que cumplió la música fariana para la organización FARC-EP, sus integrantes y su trabajo político-militar durante su periodo como grupo armado ilegal? Aquí proponemos que la música (entendida como sonido y práctica ${ }^{3}$ ) cumplió un papel fundamental para afianzar la cohesión grupal de la insurgencia, para animar e inspirar a sus miembros y para sostener una identidad colectiva entre sus distintas estructuras político-militares. Un elemento que cotidianamente circulaba en los campamentos y las actividades diarias de los miembros de la organización, no solo a nivel rural sino también urbano.

La evidencia se sustenta en un trabajo sistemático de revisión de fuentes primarias y secundarias, observación participante en 6 "conciertos farianos" y una serie de entrevistas realizadas a antiguos combatientes y miembros activos de las FARC, ahora convertido en partido político. Buscamos comprender la experiencia de estas personas con la música de la organización en sus tiempos de militancia política y militar.

\footnotetext{
1 Podríamos afirmar que el caso mexicano es sobre el que más desarrollo de literatura existe. Algunos estudios se han centrado en los corridos de la revolución mexicana de principios del S.XX: Aurelio González, "Caracterización de los héroes en los corridos mexicanos", Caravelle 72, 1999, 83-97; Max Parra, "Pancho Villa y el corrido de la revolución", Caravelle 88, 2007, 13949. Otros han trabajado las dimensiones culturales del proyecto zapatista en Chiapas y a nivel internacional: Andrew Green, "Rage Against The Machine, Zapatismo, and the Aesthetics of Anger", Popular Music 34:3, 2015, 390-407; Andrew Green, "Producing an Other Nation: Autogestión, Zapatismo, and Tradition in Home Studio Music-Making in Mexico City", Popular Music and Society, 2017, 1-20; Catalina Héau Lambert y Gilberto Giménez, "El cancionero insurgente del movimiento zapatista en Chiapas. Ensayo de análisis sociocrítico", Revista Mexicana de Sociología 59:4,1997, 221-44.

2 Al respecto véase el Dossier No.41 de esta revista, titulado "Comunicación y movimientos guerrilleros en América Latina: propuestas teórico-metodológicas y perspectivas de investigación”.

${ }^{3}$ En esta investigación asumimos la música como sonido producido y organizado, y como práctica. Es decir, entendemos que los combatientes no solo escuchaban la música fariana previamente grabada, sino que también hacían parte de orquestas, cantaban, componían en sus tiempos libres y compartían experiencias -como el baile- alrededor de ella.
} 
Pese a que hoy en día la música fariana es altamente estigmatizada por la proveniencia de sus intérpretes y las letras de las canciones ${ }^{4}$, consideramos que las canciones guerrilleras hacen parte de nuestro patrimonio artístico nacional y por tanto deben ser investigadas y visibilizadas por al menos tres razones académicas y una razón política, profundamente imbricadas. En primer lugar, porque dan cuenta, desde otra orilla y otras voces, de los acontecimientos de una guerra larga y dolorosa que ahora nos encontramos tratando de superar. Las canciones insurgentes son, en parte, la memoria viva de un actor del conflicto. Memoria que debe ser reconocida en el escenario de transición.

En segunda instancia, porque constituyen una puerta de entrada para indagar y descubrir facetas desconocidas de la organización, así como elementos cotidianos de la vida insurgente que aún no han sido investigados o suficientemente valorados por la comunidad académica en tanto se consideran secundarios. El postconflicto nos da la oportunidad de analizar la importancia de procesos como la cultura y la recreación en la construcción de la organización armada accediendo a músicos, pintores y otros artistas insurgentes. Conocer otro tipo de mecanismos para la construcción de la comunidad fariana, más allá de los mecanismos violentos de cohesión y producción social de la violencia que dominan los análisis académicos recientes, constituye un avance importante en el entendimiento del conflicto armado y sus dinámicas.

En tercer lugar, y relacionado con lo anterior, porque la variada y regionalmente diferenciada producción musical fariana abre la pregunta sobre el lugar de la música popular, y en general del repertorio simbólico ${ }^{5}$ de la organización, en los territorios donde operó. Nos acercamos, así, a comprender más detalladamente elementos del trabajo político de masas de la insurgencia hacia la población civil y la manera en que afrontó el desafío de tejer lazos y solidaridades con las variadas y diversas sociedades regionales del país.

La razón política alude a un ejercicio de re-presentación de los excombatientes de las FARC-EP en el postconflicto. Altamente estigmatizados por la población, deshumanizados por los medios de comunicación y frecuentemente observados desde la investigación social como amenazas a la seguridad en escenarios de transición ${ }^{6}$, re-presentar a los excombatientes como oyentes y amantes de la música en ejercicios académicos de esta índole es un paso más hacia el reconocimiento del "otro". Un "otro" con gustos, pasiones y sueños. Personas que demandan ser reconocidas como parte de la nación colombiana y que no son "radicalmente distintas" al resto de sus habitantes". Avanzar en este reconocimiento es, sin duda alguna, necesario y urgente para caminar hacia la reconciliación del país.

El texto se organiza en cinco secciones. En la primera, discutimos la literatura relativa a la relación entre música y política, situando el estudio de las funciones y usos de la música para los movimientos armados. En la segunda presentamos un breve contexto del surgimiento y desarrollo histórico de la música de las FARC-EP. En un tercer momento exponemos la metodología usada para el estudio. En el cuarto acápite nos concentramos en describir los resultados empíricos, identificando primero las

\footnotetext{
4 Basta con observar los comentarios en redes sociales de miles de colombianos que se oponen a la circulación de esta música ya que, a su juicio, proviene de "terroristas", "narcotraficantes" y "asesinos", según sus palabras. Por ejemplo, sobre la canción "la Guaneña de las FARC" -subida a la plataforma Youtube- un usuario expresaba: "Que desgracia con estos narcoterroristas, hasta para eso son malos, que porquería ... que tristeza tenga al país sumido en la pobreza...Malditos asesinos" Los Compañeros de las FARC-EP - La Guaneña, 2012, https://www.youtube.com/watch?v=fIZY9FTKctc.. En un sentido similar se expresaba otro usuario en la canción "Compañero Nuevo" de Cristian Pérez: "debe estar cantándole al diablo allá en el infierno" Compañero nuevo FARC-EP, 2011, https://www.youtube.com/watch?v=M58C1YOzo2Y.

5 Zachariah Mampilly, "Performing the Nation-State: Rebel Groups and Symbolic Sovereignty", Ana Arjona, Nelson Kasfir y Zachariah Mampilly (eds.), Rebel Governance in Civil War, Cambridge, Cambridge University Press, 2015, 74-97.

${ }^{6}$ Enzo Nussio, "Ex-combatants and violence in Colombia: are yesterday's villains today's principal threat?" Third World Thematics: A TWQ Journal 3:1, 2017, 1-18.

7 Ingrid Johanna Bolívar, "Unheard Claims, Well-Known Rhythms: The Musical Guerrilla FARC-EP (1988-2010)", Andrea Fanta, Alejandro Herrero-Olaizola, y Chloe Rutter-Jensen (eds.), Territories of conflict: traversing Colombia through cultural studies, Rochester, University of Rochester Press, 2017, 209-220.
} 
funciones y usos de la música fariana para la militancia y luego para el trabajo con la sociedad civil. Finalmente damos paso a las conclusiones.

\section{La relación música y política: situando el estudio de los usos y funciones de la música producida por los grupos armados}

Aunque latente desde procesos políticos de larga data -como el nacional-socialismo alemán, la segunda guerra mundial, el régimen soviético, el apartheid o las campañas electorales entre otros ${ }^{8}$ la relación música-política era generalmente vista de manera coloquial y solo recientemente ha surgido la preocupación por estudiarla sistemáticamente. Desde aproximaciones propias de la musicología ${ }^{9}$, los estudios culturales ${ }^{10}$, la sociología y recientemente la ciencia política ${ }^{11}$, diversos académicos han tratado de establecer tanto la naturaleza como la importancia de analizar este particular.

En general, la literatura distingue dos niveles en los cuales es posible notar esta relación: el nivel textual -o semántico- derivado de las letras y el nivel de la práctica, entendida como las acciones en las que músicos y canciones se involucran en asuntos políticos determinados. Sobre el primero algunos consideran que, al estar la política y la música presentes en las esferas sociales, la primera tiene incidencia sobre la segunda. En este sentido podríamos leer las canciones como "crónicas de época"12, que son escritas por sus autores con intenciones de plasmar posiciones políticas y visiones sobre el contexto en el que fueron compuestas. Aquí también podrían situarse algunos géneros musicales o canciones que en sus letras hacen referencia explícita a movimientos o causas político-sociales, y que buscan cuestionar o confrontar el poder establecido ${ }^{13}$ llamando a la acción política y la movilización social. En esta aproximación las letras de las canciones hacen las veces de mensaje, de posición ideológica, y su análisis implica articular los contenidos textuales a los contextos donde surgen y circulan.

Al pensar la música como una práctica aparecen nuevas problemáticas. Así, puede encontrarse el uso de la música como propaganda electoral ${ }^{14}$, el involucramiento de artistas reconocidos con causas político-sociales o con jefes de Estado ${ }^{15}$, y los procesos de censura realizados por diversos regímenes democráticos o dictatoriales- frente a ciertos géneros musicales o canciones ${ }^{16}$. También, los ejercicios emancipatorios o de resistencia que algunos artistas vienen realizando en la ejecución misma de sus

\footnotetext{
8 John Street, "Fight the Power': The Politics of Music and the Music of Politics”, Government and Opposition 38:1, 2003, 113-30. 9 James Currie, Music and Politics, Routledge Handbooks Online, 2011; Silvia Herrera Ortega, "Un acercamiento al estudio y análisis de la relación música-política", Revista Folios 23, 2011; Jonathan Pieslak, Radicalism and Music: An Introduction to the Music Cultures of Al-Qa'ida, Racist Skinheads, Christian-Affiliated Radicals, and Eco-Animal Rights Militants, Connecticut, Wesleyan University, 2015; Federico Reuben, "Imaginary Musical Radicalism and the Entanglement of Music and Emancipatory Politics", Contemporary Music Review 34:2-3, 2015, 232-46; Joshua Katz-Rosene, From Protest Song to Social Song: Music and Politics in Colombia, 1966-2016", Tesis doctoral, CUNY, 2017.

${ }^{10}$ John Hutnyk y Sanjay Sharma, "Music \& Politics: An Introduction”, Theory, Culture \& Society 17:3, 2000, 55-63; Garhe Osiebe, "The opportunism of political music culture in democratic Nigeria", Joumal of African Cultural Studies 28: 1, 2016, $13-27$.

11 Ted Brader, "Striking a Responsive Chord: How Political Ads Motivate and Persuade Voters by Appealing to Emotions", American Journal of Political Science 49:2, 2005, 388-405; John Street, Music and Politics, Cambridge, Polity Press, 2012.

12 Herrera Ortega, op.cit., 49.

13 Peter Manuel, "World Music and Activism Since the End of History [sic]", Music and Politics 11:1, 2017.

14 Blankenship Courtney y Renard Stan, "Pop songs on political platforms", Journal of Popular Music Studies 29:3, 2017; Deaville James [et al.], "Making sense of 2016: Perspectives on popular music and the presidential campaigns", Journal of Popular Music Studies 29:3, 2017.

${ }^{15}$ John Street, "Bob, Bono and Tony B: The Popular Artist as Politician”, Media, Culture \& Society 24:3, 2002, 433-41. Gary Osiebe, "The opportunism of political music culture in democratic Nigeria", Journal of African Cultural Studies 28:1, $2016,13-27$. 16 Annemette Kirkegaard y Jonas Otterbeck, "Introduction: Researching Popular Music Censorship", Popular Music and Society 40: 3, 2017, 257-260.
} 
composiciones ${ }^{17}$ y la creación de canciones -o apropiación de otras ya existentes- por parte de organizaciones sociales para acompañar sus luchas y reivindicaciones ${ }^{18}$.

Precisamente en el amplio panorama temático de estudios recientes que vienen explorando esta relación, las investigaciones sobre música y movimientos sociales (principalmente provenientes de la sociología y la musicología) han sido particularmente fructíferas para dilucidar los usos y funciones que tienen estos sonidos en sus prácticas políticas y repertorios de acción. Para los militantes o comprometidos, la música ha cumplido un papel importante en el mantenimiento de su espíritu, en la educación propia y en el reavivamiento de emociones que reafirman su compromiso con la lucha política ${ }^{19}$. También, en el fortalecimiento del sentido de pertenencia e identificación de estos individuos con la colectividad, mediante experiencias colectivas ${ }^{20}$.

Hacia los no comprometidos, la música ha sido utilizada como una "forma altamente afectiva y efectiva de propaganda" 21 . Ha sido importante para reclutar nuevas personas para las organizaciones (particularmente jóvenes), para atraer recursos financieros, para llamar a la movilización o acción política, y para educar de manera alternativa: presentando hechos, cuestionando las formas tradicionales en que estos se han entendido y agrupando ideas o eventos de manera creativa ${ }^{22}$. Además para compartir una particular visión del mundo, buscando cambiar las "actitudes cognitivas del escucha hacia una ideología particular"'23.

Aunque pocas respecto al volumen de estudios sobre música y movimientos sociales, las investigaciones sobre el papel de la música en las organizaciones armadas y guerras civiles ha descubierto funciones similares a las enunciadas por esta literatura. Estudios sobre el caso de Sierra Leona ${ }^{24}$, la experiencia de los soldados estadounidenses en Irak y Afganistán ${ }^{25}$ y los procesos revolucionarios en Centroamérica de los años 80 s y 90 s 26 han mostrado que la música se usó para reclutar combatientes, motivar y moralizar a las tropas en los entrenamientos y en el combate, educar -de manera informal- a los miembros de las organizaciones y elevar su conciencia revolucionaria. De igual manera para sus momentos de ocio, tiempo libre y compartir colectivo: componiendo, grabando y editando canciones o apropiándose de otras famosas para adaptar las letras a sus propias vivencias en la guerra.

Respecto al trabajo político y militar de las organizaciones hacia "afuera" - es decir, enemigos y sociedad civil- la música hizo parte de estrategias de terror y acompañó actos de violencia ${ }^{27}$. Por ejemplo, los militares estadounidenses usaban metal a todo volumen como una estrategia psicológica para minar la voluntad de los extremistas islámicos mientras que el Revolutionary United Front (RUF) ejecutaba

\footnotetext{
17 Reuben, 2015, op.cit.

18 Ron Eyerman, "Music in Movement: Cultural Politics and Old and New Social Movements", Qualitative Sociology 25:3, 2002, 443-58.

${ }^{19}$ Rob Rosenthal, "Serving the movement: The role(s) of music", Popular Music and Society 25:3-4, 2001, 11-24.

${ }^{20}$ Eyerman, 2002, op.cit.

21 Pieslak, op.cit., 203.

22 Ugo Corte y Bob Edwards, "White Power Music and the Mobilization of Racist Social Movements", Music and Arts in Action 1:1, 2008, 4-20; Rosenthal, 2001, op.cit.

23 Pieslak, op.cit, 216.

${ }^{24}$ Cornelia Nuxoll, “We Listened to it Because of the Message': Juvenile RUF Combatants and the Role of Music in the Sierra Leone Civil War", Music and Politics 9:1, 2015.

${ }^{25}$ Lisa Gilman, My Music, My War: The Listening Habits of U.S. Troops in Iraq and Afghanistan, Wesleyan University Press, 2016; Jonathan Pieslak, "Sound Targets: Music and the War in Iraq", Journal of Musicological Research 26:2-3, 2007, 123-49; Jonathan Pieslak, Sound Targets: American Soldiers and Music in the Iraq War, Bloomington, Indiana University Press, 2009.

26 Paul Almeida y Ruben Urbizagastegui, "Cutumay Camones: Popular Music in El Salvador's National Liberation Movement", Latin American Perspectives 26:2, 1999, 13-42; Robert Pring-Mill, “The Roles of Revolutionary Song - a Nicaraguan Assessment”, Popular Music 6:2, 1987, 179-89; Matías Señorán Villalba, The Role of Nicaraguan Protest Music in the Insurrection of 1979, Tesis de maestría, Warwick University, 2015.

27 Sobre el caso colombiano se tienen registros judiciales y de prensa de que actos de violencia como la masacre de El Salado fueron cometidas por los grupos paramilitares mientras escuchaban vallenatos a todo volumen y celebraban con cantos, bailes y alcohol dichos crímenes (Caracol Radio, 19 de septiembre de 2009).
} 
tambores y música Bubu para anunciar su llegada y luego desplazar a la población civil en Sierra Leona ${ }^{28}$. En los casos latinoamericanos, la música difundió a nivel internacional los acontecimientos de la confrontación ${ }^{29}$ y conectó a las organizaciones insurgentes con la población civil simpatizante. Compuestas en ritmos populares, las canciones proveyeron marcos de acción colectiva y repertorios tácticos o de contención de la guerrilla en El Salvador ${ }^{30}$, mientras que en Nicaragua sirvieron como medios didácticos de instrucción militar para los apoyos urbanos y rurales del sandinismo.

En Colombia, pese a que la música relacionada con los movimientos armados recientemente empieza a ser explorada de manera sistemática, todavía no existen indagaciones sobre los usos y funciones de esta para las organizaciones. Centrados en el análisis textual de las canciones se encuentran hoy los estudios de Villanueva ${ }^{31}$, quien recopila un amplio repertorio de canciones y poemas escritos por las guerrillas liberales del Llano en las décadas del 50 y 60, y Samacá32, que analiza en algunas canciones seleccionadas de las FARC los referentes ideológicos de marxismo y antiimperialismo, propios del contex to de Guerra Fría. Desde otro ángulo se sitúa el texto de Bolívar ${ }^{33}$, quien desde un análisis de la trayectoria organizativa de las FARC observa cómo la producción musical de esta guerrilla-en sus ritmos, letras y prácticas sociales asociadas- conectó a la organización y sus combatientes con los modos de "ser" de las sociedades regionales, la nación colombiana y la historia de su cultura popular.

\section{Contexto: la música de las FARC-EP en perspectiva histórica}

Formada principalmente por una base agraria y campesina, es imposible rastrear el momento preciso en el que irrumpe la práctica musical o de escucha en las FARC-EP, o se compone la primera canción propia de la guerrilla. Estudios previos como los de Pablo Mora ${ }^{34}$ han notado como la tradición oral ha mantenido viva, en la memoria colectiva de las comunidades rurales del Tolima y Ariari, composiciones que en los años 50s se habían dedicado a los bandoleros que quedaron después del fracasado proceso de amnistía con Gustavo Rojas Pinilla. Así pues, es posible que antes de los años 80s -década en que se conoce la primera producción musical fariana- los combatientes ya hubiesen escrito y circulado música que hiciera referencia a la organización o a sus experiencias en la guerra. Por tanto, lo que presentamos acá es el proceso de institucionalización que realiza la organización para la promoción de una cultura propia (cultura fariana) y la primera producción física de cantos insurgentes que circula y se difunde hacia la sociedad civil.

Desde finales de la década del setenta las FARC-EP venían en un proceso interno de proyección como ejército revolucionario en etapa ofensiva, en un contexto tanto de intensificación de la movilización social como de la represión y la instauración de la Doctrina de Seguridad Nacional en el país ${ }^{35}$. En la sexta conferencia -realizada en 1978- la organización había definido la necesidad de expandirse territorialmente, llegar a las ciudades, crecer en número hombres y cualificar su capacidad política y militar. También había proyectado el compendio normativo que regiría posteriormente la vida cotidiana de la tropa: el estatuto, las normas internas de comando y el reglamento de régimen disciplinario.

28 Pieslak, 2007, opc.cit, Nuxoll, 2015, op.cit.

${ }^{29}$ Eudald Cortina, "Comunicación insurgente en América Latina: un balance historiográfico y una propuesta metodológica para su estudio", Izquierdas 41, 2018, 4-43.

30 Almeida y Urbizagastegui, 1999, op.cit.

31 Orlando Villanueva, Canciones de la guerra: la insurrección llanera cantada y declamada, Bogotá, Universidad Distrital Francisco José de Caldas, 2016.

32 Gabriel Samacá, "Versos de amores que matan los odios malditos del yanqui opresor: música insurgente y discurso político de las FARC-EP”, Anuario Colombiano de Historia Social y de la Cultura 44:2, 2017, 227-59.

33 Bolívar, 2017, op.cit.

34 PABLO MORA 1998

35 Carlos Medina Gallego, FARC-EP: notas para una historia política, 1958-2008, Bogotá, Universidad Nacional de Colombia, 2009. 
Con un aumento sostenido de combatientes, la organización se enfrentaba entonces al reto de cohesionar social e ideológicamente a un ejército revolucionario que cada vez copaba más territorios y necesitaba adaptar su táctica y estrategia a las nuevas formas de operar del Ejército Nacional ${ }^{36}$. En este sentido se plantea la VII Conferencia, realizada en 1982 con el fin de consolidar la estrategia revolucionaria que se había planteado en 1978 pero que no había logrado cumplirse a cabalidad en el transcurso de esos cuatro años.

En esta Conferencia -que posteriormente es reconocida como una de las más importantes para el avance organizativo de la guerrilla- y aparte de toda la reconfiguración estratégica para virar hacia la ofensiva militar ${ }^{37}$, las FARC-EP reconocen por primera vez la importancia de la cultura en la cualificación del nivel político de los combatientes. Según la organización, una de las principales dificultades a las que se enfrentaba el movimiento era el de la falta de metodología científica en la "transmisión y asimilación de conocimientos"38. Así, la insurgencia dictamina que se deberá incluir en el horario diario de cada frente -y acompañado de otras prácticas educativas como la creación de bibliotecas - una hora diaria de cultura. En esta hora, que se conocerá como la hora cultural, se esperaba que se abordaran temas relacionados con la política, historia y actualidad, pero también se educara en canto y poesía ${ }^{39}$. La importancia de la cultura quedará, además, plasmada en el Estatuto de la organización, donde un deber del combatiente será el "hacer esfuerzos para superarse en los terrenos político, cultural y militar" 40 .

De la misma manera que existía una reflexión organizativa sobre la necesidad de vincular la cultura a los procesos de formación política, la guerrilla también reconoció que hasta ese momento su política de trabajo de masas era insuficiente y que era necesario darle un nuevo impulso, ajustada a la fuerza que estaba ganando el movimiento para ese entonces. Dentro de esta nueva estrategia de propaganda también la cultura iba a jugar un papel fundamental. El documento, por ejemplo, invitaba a que los diseños de los boletines fueran más amables con los lectores, incluyendo dibujos, fotos y caricaturas para hacer llegar más fácil su mensaje. También recomendaba diversificar la oferta de propaganda a afiches, murales y cassetes, y avanzar en la consolidación de la emisora propia.

Como se puede notar, las conclusiones emanadas de la VII Conferencia empiezan a institucionalizar la cultura en el proceso interno de formación y en el trabajo de propaganda y de masas, pero aún no han regulado los contenidos de estos procesos. Es decir, aún no se habla de promover una cultura propia o "cultura fariana", por lo cual en la vida cotidiana de la guerrilla se abren espacios culturales que, para el caso de la música, siguen bebiendo exclusivamente de la música popular que circulaba en las regiones donde operaba cada uno de los frentes. Esta situación la ejemplifica muy bien un testimonio de un entrevistado que ingresó a la organización en el año 1986 y operó en el departamento de Cundinamarca: "la música que se escuchaba en frentes de cordilleras era toda esa música de carrilera, del Caballero Gaucho, de Alci Acosta, música de despecho, amor también. No había una música propia”41

\footnotetext{
36 Juan E. Ugarriza y Nathalie Pabón, Militares y Guerrillas: La memoria bistórica del conflicto armado en Colombia desde los archivos militares 1958 - 2016, Bogotá, Universidad del Rosario, 2017.

37 En el Plan Cisne 3, que se produce en dicha Conferencia, la organización afirmaba: "con el nuevo modo de operar las FARC se hacen totalmente ofensivas y menos defensivas. Ya no estarán a la espera de un enemigo diluido, audaz y escurridizo, dueño, por su conocimiento, del terreno, y con suficiente y clara inteligencia de combate. Dejaríamos de estar buscando terrenos cien por cien ventajosos que, en las condiciones de hoy, un enemigo diestro sabe burlar, sino buscando al enemigo, siguiéndolo en sus movimientos para cazarlo en el momento que él menos espere". FARC-EP, Plan cisne 3 para 21 días, del 4 al 25 de agosto de 1980, 1980. Disponible en: http://www.farc-ep.co/septima-conferencia/plan-cisne-3-para-21-dias-del-4-al-25-de-agosto-de1980.html

38 FARC-EP, Conclusiones de educación de la Séptima Conferencia Nacional de las FARC-EP, 1982. Disponible en: http://www.farcep.co/septima-conferencia/conclusiones-de-educacion-de-la-septima-conferencia-nacional-de-las-farc-ep.html 39 Idem.

40 FARC-EP, Estatuto de las Fuerzas Armadas Revolucionarias de Colombia - Ejército del Pueblo - (FARC-EP)", 1982. Disponible en: http://www.farc-ep.co/octava-conferencia/estatuto-farc-ep.html.

${ }^{41}$ Entrevista 08, excombatiente, 25 de noviembre de 2017.
} 
No fue sino hasta inicios del año 1988 cuando se tiene conocimiento de las primeras producciones discográficas de la canción fariana. Derivado de los Acuerdos de la Uribe, las FARC-EP están en un momento de consolidación en el ámbito político-electoral con el partido Unión Patriótica (UP) y en el militar con la Coordinadora Guerrillera Simón Bolívar (CGSB), proceso de convergencia de seis guerrillas colombianas ${ }^{42}$. Además, están en búsqueda de conectarse con nuevos referentes identitarios latinoamericanos y nacionales que dieran horizonte ideológico a su organización en un contexto de crisis del socialismo internacional.

Es en este marco que sale a la luz el primer cassete insurgente, empíricamente producido en la Sierra Nevada de Santa Marta y que tuvo una circulación restringida entre simpatizantes del movimiento. El material de este servirá luego para la producción en estudio y posterior lanzamiento de "Mensaje fariano", trabajo con el que se inaugura oficialmente la producción musical fariana, ya que tiene un propósito real de difusión entre la tropa y la sociedad. Según Lucas Iguarán, uno de los músicos participantes, las canciones que recoge este cassete "ya tenían un tránsito por los campamentos, en las horas culturales y en los ratos de esparcimiento con los combatientes" ${ }^{43}$. Las canciones que contiene este primer trabajo -de ritmos vallenatos- responden al contexto que estaba viviendo la organización. Por ejemplo, se encuentran composiciones como "Regreso Simón", en donde Julián Conrado rescata la imagen de Simón Bolívar como símbolo de la unidad que se estaba gestando en la CGSB o "Mensaje Fariano", en donde la organización reitera su voluntad de avanzar en caminos para la construcción de la paz.

Dos años más tarde, y con la muerte de Jacobo Arenas, se grabarán paralelamente dos trabajos que sumarán a la creciente discografía insurgente: "500 años" de Julián Conrado y "Para todo mi pueblo" de Lucas Iguarán, producciones que siguen manteniendo los ritmos caribeños para enmarcar letras que abordaban temáticas relacionadas con la invasión europea a América Latina y la resistencia indígena, los diálogos de Caracas entre el Gobierno y la CGSB, y homenajes al recién fallecido comandante ${ }^{44}$.

Con tres producciones farianas ya realizadas y un aprendizaje importante en términos del impacto que pueden tener sus producciones musicales para conectarse con las sociedades regionales principalmente del Caribe colombiano ${ }^{45}$-, la organización llegará a la VIII Conferencia Nacional del año 1993 para institucionalizar de manera explícita y definitiva la promoción de una cultura propia, la cultura fariana. Las conclusiones de esta conferencia evidencian que la cultura ya no se encuentra, como en la anterior conferencia, supeditada a la formación política, sino que ya adquiere autonomía propia como parte de un proceso de construcción de un combatiente integral. Esto se expresa con claridad en el Punto No.10 de las Conclusiones Generales: Fomentaremos la cultura fariana que se expresa a través de la música, la poesía, el cuento oral y escrito, el teatro, para difundirla en las horas culturales, en las reuniones de célula, en actos con la población y por medios como RESISTENCIA, revistas, casetes, discos y videos 46

Del mismo modo, la lectura del trabajo de propaganda o trabajo de masas también tendrá un giro importante. Aparte de fomentar la promoción de la cultura propia y erigir la emisora como el principal medio de difusión, las FARC-EP reconocen explícitamente la necesidad de diseñar propaganda regionalmente diferenciada, adaptada a las particularidades de cada contexto territorial para hacerla más

\footnotetext{
42 En la CGSB participaban las FARC junto al Ejército de Liberación Nacional - ELN, el Ejército Popular de Liberación-EPL, el Movimiento 19 de abril - M-19, el Movimiento indígena Quintín Lame - MAQL y el Partido Revolucionario de los Trabajadores - PRT

43 CRB, Entrevista al Cantautor Guerrillero Lucas Iguarán. - FARC-EP Bloque Martín Caballero, 2007. Disponible en: https://resistencia-colombia.org/medios/crb/1098-entrevista-al-cantautor-guerrillero-lucas-iguaran.

${ }^{44}$ Idem.

45 Bolívar, 2017, op.cit.

46 FARC-EP, Octava Conferencia Nacional de Guerrilleros: conclusiones generales, 1993. Disponible en: http://www.farc-ep.co/octavaconferencia/octava-conferencia-nacional-de-guerrilleros.html.
} 
efectiva: "que su contenido tome aspectos nacionales y de las regiones realzando sus luchas y sus logros; tomando aspectos políticos, económicos, sociales y culturales sin ser monótonos ni pesados" 47.

Aunque nuestra unidad de análisis principal no es la música fariana como producto musical sino la experiencia de los militantes con ella, es importante caracterizarla brevemente tanto en sus ritmos como en su contenido. A nivel de ritmos podemos hablar de una música profundamente diversificada, conectada con los sonidos populares de las regiones y que responde a la amplia variedad de géneros que componen la geografía sonora del país ${ }^{48}$. Si bien es cierto que el vallenato es el género musical en el que más se ha compuesto la música fariana (particularmente por la prolífica actividad de artistas guerrilleros provenientes del Caribe como Julián Conrado, Cristian Pérez y Lucas Iguarán), también encontramos otros ritmos de igual significación para la cultura popular nacional tales como la cumbia, música andina, llanera y la llamada "música popular". Otros ritmos como la salsa, el merengue, la ranchera y la norteña también han tenido un lugar en las composiciones de los insurgentes. Inclusive, recientemente han irrumpido géneros urbanos como el rap y el reggae de la mano de jóvenes artistas guerrilleros como Martín Batalla y Blackesteban.

No es casualidad que los ritmos usados por cada uno de los cantantes y agrupaciones farianas también coincidan con la cultura musical de las regiones en donde los frentes de estos artistas operaban ${ }^{49}$. Por ejemplo, los Rebeldes del Sur preferían el uso de ritmos norteños y de música popular ya que desarrollaban su accionar político-militar en departamentos como el Caquetá, Putumayo y Huila. Allí, estos sonidos a la vez que están profundamente arraigados en los hábitos de escucha de pueblos y veredas se conectan con otras culturas musicales circundantes, como la del "narco" o la del "raspachín".

En el nivel de contenido, los temas son igual de variados. Desde canciones que retratan la situación social y política del país, denuncian el intervencionismo extranjero, exaltan a los líderes históricos de la guerrilla, relatan acciones militares o hablan de la vida cotidiana en los campamentos, particularmente en temas de amor y mujeres guerrilleras. También se encuentran canciones típicas del folclor colombiano apropiadas y modificadas en su nivel textual por la organización ${ }^{50}$, práctica ya observada anteriormente por otros investigadores en los contextos de Sierra Leona e Irak ${ }^{51}$.

Además del material grabado y disponible principalmente en internet, la investigación permitió constatar la existencia de múltiples composiciones musicales de los combatientes rasos. Aunque es imposible determinar si fueron creadas en el marco de su proceso educativo cultural o por simple placer, gusto e inspiración, lo cierto es que estas canciones nunca fueron grabadas y tampoco pudieron circular más allá del frente al que pertenecían. Este material sonoro "efímero" se enfoca, principalmente, en celebrar acciones militares y poetizar así la experiencia personal de cada combatiente en la confrontación armada.

\section{Metodología y fuentes}

La discusión reciente sobre música y política nos ilumina en tres niveles de posible análisis de esta relación: el nivel de la creación y materialización del producto cultural, el textual de las canciones y el de los oyentes o la "audiencia" 52 . Este texto responde a este último nivel, debido a que nos interesa reconstruir la experiencia de los miembros de la guerrilla con el producto musical, y no tanto el proceso

\footnotetext{
47 Idem.

48 Bolívar, 2017, op.cit.

${ }^{49}$ Investigaciones anteriores han mostrado como la eficacia de transmitir los contenidos textuales ideologizados de las canciones se relaciona con las propiedades sonoras o ritmos en los que se enmarcan, en la mayoría de casos aquellos familiares o del gu sto de las audiencias a las quienes impactar. Véase Almeida, 1999, op.cit; Pieslak, 2015, op.cit.

${ }^{50}$ Idem.

51 Nuxoll, 2015, op.cit, Pieslak, 2009, op.cit.

52 Ortega, 2015, op.cit.
} 
de cómo se construyeron las canciones ni lo que dicen estas en su nivel textual. Así, la presente investigación se desarrolla a partir de la metodología cualitativa, particularmente a partir del uso de herramientas de recolección de información como la observación participante y las entrevistas, sugeridas previamente por la literatura de música y movimientos sociales como vías para comprender de una mejor manera la forma en que los sonidos afectan a la audiencia ${ }^{53}$.

La primera, usada principalmente en estudios de la antropología y la sociología, permite al investigador tener un conocimiento profundo de las dinámicas internas de un grupo social mediante la inmersión del mismo en sus prácticas. En total asistimos a cinco conciertos en la ciudad de Bogotá en donde artistas farianos se han presentado. Entre estos eventos se incluyen los dos conciertos que el cantautor vallenato Julián Conrado ha dado en la capital, el lanzamiento del partido político en la plaza de Bolívar, el estreno del videoclip "Desenterrando memorias parte II" del rapero fariano Martín Batalla y la conmemoración de los 10 años de fallecimiento de Manuel Marulanda Vélez. Adicional a estos eventos, participamos durante 8 días a la X Conferencia de las FARC, celebrada en las Sabanas del Yarí durante el último semestre del año 2016. En este escenario el pleno de la guerrilla decidió su adhesión colectiva a los acuerdos alcanzados en La Habana.

En los espacios de conciertos y eventos a los que se acudió se llevó un registro en diario de campo sobre las impresiones y descripciones de los lugares, los asistentes y el evento en general. También se grabaron en medios magnéticos estos eventos para soportar los análisis escritos.

Frente a las entrevistas, esta investigación entiende a las FARC-EP como una organización política amplia, la cual incluye tanto al ejército en armas como las estructuras políticas amplias (Movimiento Bolivariano-MB, Partido Comunista Clandestino- PC3, Milicias Populares y Milicias Bolivarianas). Conversaciones iniciales con integrantes de la organización nos mostraron que la música cumplió un papel diferente según el tipo de estructura donde ellos estaban inscritos y según sus propias experiencias. Teniendo presente esa diversidad, buscamos entrevistar tanto a excombatientes que hicieron parte de las FARC-EP (desmovilizados individuales y miembros actuales del partido) como a jóvenes militantes urbanos y clandestinos que hacían parte de las estructuras políticas de la organización. También buscamos entrevistar a músicos de distintos bloques del país para que complementaran con su visión el tema trabajado.

El diseño de las entrevistas buscó reconstruir la trayectoria del entrevistado con la música fariana, a partir de su experiencia en la organización. Se les preguntó sobre el papel que ellos le asignaban a la música en la historia de la organización y si creían que esta había cumplido algún rol en el trabajo políticomilitar. Fueron entonces los integrantes de las FARC quienes nos explicaron los efectos o desarrollos que la música y la práctica musical había tenido entre ellos.

Para efectos de la investigación, fue necesario reducir las preguntas de la entrevista a la música de los grupos armados, también llamada canto insurgente ${ }^{54}$. Es decir, la música compuesta, ejecutada y -en algunas ocasiones- producida por las mismas organizaciones armadas. Hasta ahora las investigaciones no han realizado esta distinción, pero creemos que es importante hacerla por razones tanto analíticas como procedimentales. Analíticas, porque creemos que el sentido de identificación (del "nosotros") que transmiten estas canciones sí establece una distinción -en la escucha y en lo que genera en los combatientes- frente a otras canciones que circulan en la cotidianidad de los grupos armados, pero que en su nivel textual no hace referencia a eventos, valores, héroes u horizontes de la misma organización.

Procedimentales, ya que precisamente nos interesaba que los entrevistados nos compartieran primordialmente su experiencia con este tipo de música, aunque en sus testimonios no sea fácil establecer una distinción tajante entre momentos de escucha y práctica de la canción insurgente y de otras canciones que hacen parte del repertorio musical de la cultura popular colombiana o de algunas subculturas urbanas.

\footnotetext{
53 Rosenthal, op.cit., 15.
}

54 Samacá, 2017, op.cit. 
Así pues, no debemos perder de vista que nuestra pregunta por el canto insurgente se debe situar en un mapa más amplio que recuerda relaciones entre movimientos sociales, acción política, agrupaciones armadas y trayectorias de la música popular en cada país.

Realizamos un total de 14 entrevistas: 3 a músicos de la organización, 8 a excombatientes individuales y 3 a militantes urbanos. Los tres músicos hicieron parte de distintos bloques (Caribe, Magdalena Medio y Sur), por lo cual aportaron una visión amplia sobre el fenómeno. Los ocho excombatientes individuales (es decir, que se desmovilizaron por el programa de deserción promovido por el Gobierno Nacional como parte de la Política de Seguridad Democrática entre el año 2002 y 2010) operaron en los bloques Sur y Oriental, particularmente en los departamentos de Guaviare, Meta, Caquetá y Putumayo. En cuanto a los militantes urbanos, estos desarrollaron acciones políticas en las ciudades de Bogotá y Pereira, y el departamento de Caquetá principalmente.

Al transcurrir las entrevistas, tanto excombatientes como militantes urbanos fueron recomendando a otras personas que podían aportar a la investigación. Así, la técnica "bola de nieve" ampliamente utilizado en contextos de conflicto armado- fue la estrategia utilizada para sumar testimonios a nuestro trabajo. Todas las entrevistas fueron registradas por medios magnéticos, sometidas a proceso de transcripción y codificadas con el software de análisis cualitativo Atlas Ti. El proceso de codificación fue mixto, dado que algunas categorías surgieron inductivamente de los testimonios aportados por los entrevistados mientras que otras se habían establecido previamente a partir de la literatura.

Por supuesto la recolección de fuentes primarias se acompañó de una revisión sistemática y exhaustiva de fuentes secundarias, producidas por la organización y presentes en su mayoría en la web. De esta manera se consultaron documentos como los Estatutos de la organización, el Reglamento de Régimen Disciplinario, las Normas Internas de Comando y las cartillas de entrenamiento militar (orden abierto y cerrado). También, las conclusiones de las Conferencias y la Revista Resistencia. Esta última, una publicación del Bloque Caribe que presentaba partes de guerra, análisis políticos, entrevistas a guerrilleros y arte insurgente (poemas y pinturas principalmente). Se consultaron además materiales audiovisuales producidos por la insurgencia y por terceros.

\section{Hallazgos: usos y funciones de la música de las FARC-EP}

A continuación, presentamos el análisis de la música de las FARC-EP respecto a sus usos y funciones. En primer lugar, discutimos las funciones hacia la organización y sus militantes: mayor cohesión social e ideológica, mayor motivación y fortalecimiento de la identidad colectiva. Luego, exponemos las funciones que adquirió en relación a su trabajo con la sociedad civil en los territorios donde operó la insurgencia.

Es importante advertir que esta propuesta analítica no debe llevar a una lectura reduccionista del papel de la música en las organizaciones armadas. Es decir, como un elemento estrictamente "funcional" o "utilitario" para las elites de estas organizaciones. A la vez que es necesario situar la música en las complejidades socio-históricas y los contextos políticos bajo las cuales nace, circula y tiene recepción ${ }^{55}$, propuestas como las de Street ${ }^{56}$ y Allen ${ }^{57}$ nos invitan a no descuidar asuntos como el placer de la música y las posibilidades políticas que se abren con el disfrute individual y colectivo. Es decir, no se debe perder de vista que la música-como práctica estética-goza de autonomía propia y en muchas ocasiones no se

\footnotetext{
55 John Hutnyk y Sanjay Sharma, "Music \& Politics: An Introduction”, Theory, Culture \& Society 17:3, 2000, 55-63; Reuben, 2015, op.cit.

56 Street, 2003, op.cit.

${ }^{57}$ Lara Allen, "Music and Politics in Africa", Social Dynamics 30:2, 2008, 1-19.
} 
compone o se ejecuta más que por el simple placer y alegría que emana de ella, y las posibilidades de disfrute, amenización y compartir colectivo que esta posibilita ${ }^{58}$.

\section{Funciones hacia "adentro": motivación, cohesión e identidad}

En este acápite exploraremos los resultados que la música generó en los combatientes y militantes urbanos, en su relación con otros compañeros y con las distintas estructuras de la insurgencia. Identificamos al menos tres funciones en los niveles individual, grupal y organizacional. A nivel individual, la música elevó la moral y el espíritu, motivando a los combatientes a continuar en la actividad políticomilitar. En el nivel grupal -es decir, entre combatientes y militantes que hacían parte de un mismo frente o célula - fomentó la cohesión social mediante la vivencia de experiencias compartidas. Finalmente, permitió afianzar la cohesión ideológica y los lazos de los miembros con la organización armada, sus historias y sus valores. En este sentido, la música fue clave para sostener una identidad fariana, conectando a aquellos que combatían en el campo con quienes desarrollaban su trabajo en las ciudades.

\section{a. Motivación y moral de combate}

Aunque se ha dado un importante debate sobre el lugar de la "moral" en contextos de organizaciones militares ${ }^{59}$, acogemos la definición de nivel individual planteada por Manning, quien la entiende como el "entusiasmo y la persistencia con la que un miembro de un grupo se involucra en las actividades prescritas de ese grupo" 60 . Los testimonios de nuestros entrevistados evidenciaron la fuerte influencia que tuvo la música fariana para motivarlos a seguir comprometidos con la causa de la organización. En el caso del ejército revolucionario levantaba el ánimo de los guerrilleros luego de situaciones adversas o condiciones difíciles durante la confrontación armada como la soledad, la falta de la familia, la muerte de un amigo o el asedio del enemigo.

En las ciudades animaba las acciones de confrontación e infundía compromiso y conciencia del lugar e importancia que tenían la clase trabajadora y los estudiantes en la consecución de la revolución. Así como lo afirmaba el MB en una carta dedicada a Julián Conrado, la música "en cada tropel y acción nos alienta a continuar cargando la esperanza de la Nueva Colombia"61. También, la música era fuente de inspiración para que los militantes urbanos que eran músicos compusieran canciones para sus bandas de otros géneros musicales, como el rock o el punk.

Al relatar epopeyas militares como la de Marquetalia -en donde un pequeño grupo de campesinos resistió la ofensiva militar desplegada por el Ejército Nacional- los individuos se conectaban con la posibilidad de resistencia ante la adversidad total, y con más dedicación y empeño cumplían las responsabilidades que se les asignaba en el ámbito político y militar, siempre bajo el entendido de que luchaban por una causa justa y necesaria. Un entrevistado, militante urbano en Bogotá y miliciano en Caquetá, afirmaba que inclusive en ocasiones las canciones insurgentes se escuchaban previo a salir a un combate: "Había fiestas. Se podía estar en una fiesta que duraba una hora, se tomaba tres cervezas y se salía a combatir. Y fiestas no con música cualquiera, sino merengue fariano. Música de nosotros"62

\footnotetext{
58 No es el objeto central de nuestra investigación, pero también la música fue usada para la conquista amorosa entre combatientes, mediante la "dedicatoria" de algunos temas del repertorio insurgente.

59 Reuven Gal, "Unit Morale: From a Theoretical Puzzle to an Empirical Illustration-An Israeli Example", Journal of Applied Social Psychology 16:6, 1986, 549-64.

${ }^{60}$ Frederick Manning, "Morale and cohesion in military psychiatry", Franklin Jones, Military Psychiatry: Preparing in Peace for War, Department of the Army, 1994, 1-18.

${ }_{61}$ Movimiento Bolivariano, Para el camarada cantautor del pueblo colombiano, Julián Conrado - FARC-EP Bloque Martín Caballero, 2013. Disponible en: https://resistencia-colombia.org/movimiento-fariano/movimiento-bolivariano/comunicados/1162-para-elcamarada-cantautor-del-pueblo-colombiano-julian-conrado.

${ }^{62}$ Entrevista 09, militante urbano, 26 de noviembre de 2017.
} 
La organización también entendió este papel de la música para inspirar y llevó a sus artistas más reconocidos por los diferentes frentes y campamentos a cantarle a los guerrilleros. Según los testimonios de nuestros entrevistados y fuentes secundarias, tanto Julián Conrado como Cristian Pérez desarrollaron en distintos bloques campañas de "moralización" que buscaban elevar el ánimo de las tropas que combatían en toda la geografía nacional por medio de la música en vivo.

\section{b. Cohesión social y experiencias compartidas}

Tal y como lo han mostrado previos estudios, lograr altos niveles de cohesión grupal entre los miembros de una agrupación armada es fundamental para el éxito en el desempeño de tareas y cumplimiento de objetivos, y para garantizar el interés básico de sobrevivir ${ }^{63}$. Dentro de los niveles básicos de las unidades militares -o grupo primario ${ }^{64}$ - se ha notado la importancia de la cohesión social, entendida como la "naturaleza y calidad de los lazos emocionales de amistad, simpatía, cuidado y cercanía entre los miembros del grupo"65. Según las investigaciones, una mayor cohesión social permite a su vez aumentar la confianza entre los individuos, crear un sentido de responsabilidad colectivo que reduce la posibilidad de deserción, producir lazos sociales donde no existen y derribar barreras percibidas entre pares ${ }^{66}$.

En el caso de las FARC-EP encontramos que la música, entendida aquí como práctica cultural, incrementó la cohesión social por medio de experiencias compartidas entre combatientes de una misma unidad. Al fomentar "el movimiento corporal y el contacto, y la experiencia colectiva" 67 , esta se constituyó en un elemento crucial en la vida cotidiana para afianzar el sentido de camaradería y fraternidad, y para acercar emocionalmente a los miembros de la organización.

Uno de los aspectos más llamativos de la vida guerrillera fariana era el sentido colectivo que permeaba todas las actividades sociales cotidianas. Hombres y mujeres cocinaban juntos, lavaban juntos, se bañaban juntos y, por supuesto, se divertían juntos. Entre los guerrilleros que pertenecían al mismo frente las experiencias compartidas que propició la música fueron diversas. El baile animado por esta música, el canto en las horas culturales, así como los espacios de formación política y los eventos, fueron espacios en donde se compartió, se tejió confianza y amistad y se integró a la comunidad fariana. Así lo afirmaba un músico entrevistado frente al baile en la vida social insurgente: "en la guerrilla así usted baile horrible, baila y se lo goza. Y al guerrillero no le da pena bailar feo. Uno ve gente bailando horrible, horrible, pero vea: gozando y disfrutando" 68

Inclusive, procesos de composición musical colectiva entre combatientes que no eran músicos también fomentaron el afianzamiento de lazos sociales. Por ejemplo, un entrevistado que hizo parte del Frente 15 recordaba cómo entre varias unidades crearon una canción sobre el comandante "Mocho Cesar", quien guió a una tropa insurgente durante una difícil operación militar. Estas composiciones en ocasiones eran enviadas a las orquestas de músicos guerrilleros, quienes las musicalizaban y luego las circulaban en vivo o por medio de la emisora "Voz de la Resistencia" 69.

\footnotetext{
${ }^{63}$ Carlos García-Guiu, "Cohesión grupal y espíritu de cuerpo en las unidades de Seguridad y Defensa", Revista de Pensamiento Estratégico y Seguridad CISDE 2:1, 2017, 65-77; Guy L. Siebold, “The Essence of Military Group Cohesion”, Armed Forces \& Society 33:2, 2007, 286-95.

${ }^{64}$ Es decir, aquellas estructuras que tienen interacción cotidiana e interpersonal como las escuadras, guerrillas, compañías y columnas que conforman un frente para el caso de FARC-EP. Juan Guillermo Ferro y Graciela Uribe, El orden de la guerra: las FARC-EP, entre la organización y la política, Bogotá, Pontificia Universidad Javeriana, 2002, 44.

65 Milan Vego, Operational W arfare at Sea: Theory and Practice, Taylor \& Francis, 2017, 244.

${ }^{66}$ Dara Kay Cohen, “The Ties That Bind: How Armed Groups Use Violence to Socialize Fighters”, Journal of Peace Research 54:5, 2017, 701-14; Marco Jowell, "Cohesion through socialization: liberation, tradition and modernity in the forging of the Rwanda Defence Force (RDF)", Journal of Eastern African Studies 8: 2, 2014, 278-93.

${ }^{67}$ Eyerman, op.cit., 450.

68 Entrevista 05, músico, 5 de noviembre de 2017.

${ }^{69}$ Entrevista 14, excombatiente, 14 de febrero de 2018
} 
Por supuesto, el fortalecimiento de la cohesión social por medio de la música fue más poderoso entre aquellos que eran artistas y hacían parte de alguna orquesta o agrupación musical guerrillera. Estas personas compartieron con otros combatientes todo el proceso de creación de un producto musical que iniciaba desde la composición, pasaba por el ensayo de las canciones, seguía con la adecuación de lugares para poder grabar y finalizaba con la presentación en vivo de su trabajo frente a los demás guerrilleros (y en ocasiones a la sociedad civil). Así lo evidenciaba el testimonio de un músico guerrillero del Magdalena Medio, quien se refería al trabajo en equipo que existía detrás de la consolidación de la agrupación Horizonte fariano:

Trabajaban como burros, tenían que armar una casa en madera como fuera para poder grabar y llenar ese espacio de panales de huevos para que quedara con buen sonido, y buscar un sitio que no lo interrumpiera nadie. Ellos trabajaban día y noche. Así, mamados, llegaban a ensayar. Eso hace único a Horizonte en comparación con otras agrupaciones, el trabajo ${ }^{70}$

En este sentido no es casualidad, por ejemplo, que durante el proceso de desarme de las FARCEP y la concentración de tropas, músicos de la orquesta Los Rebeldes del Sur hubiesen instalado sus "caletas" (o viviendas guerrilleras) una cerca de la otra, para así estar más cerca de sus compañeros de agrupación ${ }^{71}$. Precisamente frente a ese lazo social que se forjó entre los integrantes, un músico de esta orquesta nos comentaba:

Como grupo hemos reafirmado esa armonía y la fraternidad que hemos logrado crear porque la orquesta, como lo decíamos ayer, se conformó con guerrilleros de distintos frentes, muchos que no nos distinguíamos. Pero al llegar allá creamos ese lazo de unidad indestructible que nos ha permitido fortalecer muchísimo más, como esa unidad que debe existir a nivel de FARC porque somos una sola organización, con unos mismos principios y con esto lo hemos reafirmado mucho más ${ }^{72}$

En comparación con lo acontecido en el ejército revolucionario, la posibilidad de vivir experiencias comunes o compartidas entre los militantes urbanos por medio de la música era baja, sino imposible, dada las condiciones de seguridad y de clandestinidad que debían garantizar en las ciudades. Sin embargo, y a riesgo de violar el principio de compartimentación, la música propició en contadas ocasiones la oportunidad de amenizar y disfrutar encuentros entre células que no debían haberse conocido. Así lo recuerda un militante urbano entrevistado, quien estudió en la Universidad Nacional de Colombia y vivió una experiencia musical colectiva con otros militantes de la organización en este centro educativo: "Un día terminamos tocando vallenatos farianos porque uno de los compañeros tocaba acordeón y el otro tocaba la caja. Entonces resultamos allá en el hueco del museo tocando Julián [Conrado] no más con el acordeón y con la caja. Se armó una parranda, nos dimos cuenta y había como treinta personas alli'’73

\section{c. Cohesión ideológica e identidad colectiva}

Muchos de los individuos que ingresaron a las FARC-EP no tenían una claridad ideológica sobre el propósito de la confrontación armada y los objetivos de la organización, y solo fue durante su pertenencia

\footnotetext{
70 Entrevista 02, músico, 29 de agosto de 2017.

71 "Farc, de la guerra al arte en el Putumayo", La Opinión, 12 de febrero de 2017. Disponible en: https://www.laopinion.com.co/colombia/farc-de-la-guerra-al-arte-en-el-putumayo-127883.

72 Entrevista 01, músico, 20 de septiembre de 2016.

${ }^{73}$ Entrevista 07, militante urbano, 23 de noviembre de 2017.
} 
al grupo que se ideologizaron ${ }^{74}$. Al estar la música presente en los diversos espacios de socialización de la organización, podemos afirmar que la música insurgente también permitió afianzar la cohesión ideológica de las FARC-EP, fortaleciendo así el lazo institucional (institutional bonding) del combatiente con la organización o grupo secundario ${ }^{75}$. A falta de una definición en la literatura de cohesión ideológica, proponemos entenderla como el grado de unidad y acuerdo entre los miembros de una organización armada frente a un "conjunto de creencias políticas que promueven una forma particular de entender el mundo"76.

Desde el nivel textual, el contenido ideologizado de las letras permitía a los combatientes afirmar tanto las convicciones del grupo, la lectura de la organización frente a la situación del país y el propósito de su lucha armada. En últimas, la música forjaba conciencia revolucionaria. Tal y como lo afirmaba un militante urbano que actuó como miliciano en Bogotá y Caquetá: "la música se la planteaba de una forma vallenatera o hasta bailable. Mientras bailaban la idea era que les generara conciencia y se les metiera el mensaje"'77

Entre las canciones más recordadas por nuestros entrevistados siempre están aquellas que sintonizaban a los escuchas con los objetivos político-militares de las FARC-EP y las que justificaban la necesidad de la lucha armada. Así se expresaba otro militante urbano de Bogotá sobre el contenido de algunas canciones insurgentes:

los contenidos de esas canciones traían impresa la marca ideológica fariana (...) ¿Y por qué trae impresa la marca ideológica fariana? Porque habla de la situación económica del país, porque habla de la necesidad de cambiar eso, porque relata la decisión de miles de jóvenes de involucrarse, de ingresar, de irse al monte. De sacrificar todos sus temas personales por una vaina altruista, colectiva ${ }^{78}$

Nuestros entrevistados también recuerdan algunas canciones que relatan la situación de la sociedad colombiana rural como "El Glifosato" de Julián Conrado, la cual ofrece una visión desde la insurgencia sobre los efectos nefastos del Plan Colombia y la intervención EEEUU. Otros temas musicales que los excombatientes mencionaron con insistencia son aquellos que hablan del Ejército Nacional. Discursivamente las FARC-EP siempre habían enunciado que sus enemigos no eran los soldados rasos sino la oligarquía, el enemigo de clase. Esto es patente en canciones como "Hermano Soldado" de Lucas Iguarán, en donde incluso se invita a que los combatientes del Estado se unan a la causa de la revolución. Sin embargo, es importante notar que algunos combatientes nunca se sintonizaron con la música. Es decir, que el grado de cohesión ideológica que la música ayudaba a fortalecer también estaba mediado por el nivel de compromiso y de creencia en el proyecto político fariano que tuviera el individuo luego de pasar por el proceso de socialización. Así lo afirmaba una entrevistada, la cual nunca se conectó con la música insurgente y sus contenidos debido a su experiencia negativa en la organización, pese a estar por más de 15 años allí: "hay mucha música. Pero de por si a mí, a pesar de que yo me crie, a mí no me llamaba la atención la música de por allá. Es que es difícil cuando usted está en un sitio donde está obligado y usted quiere otro horizonte y no donde está. Entonces eso no le simpatiza absolutamente nada" 79

A la vez que los contenidos textuales de la música permitieron incrementar la cohesión ideológica, también lograron generar un sentido de identidad de los combatientes con la organización.

\footnotetext{
74 Miguel Ángel Beltrán Villegas, Las FARC-EP (1950-2015): luchas de ira y esperanza, Bogotá, Ediciones Desde Abajo, 2015; Juan E. Ugarriza y Matthew J. Craig, "The Relevance of Ideology to Contemporary Armed Conflicts: A Quantitative Analysis of Former Combatants in Colombia", Journal of Conflict Resolution 57: 3, 2013, 445-77.

75 Siebold, 2007, op.cit.

76 Ugarriza y Craig, op.cit., 450.

77 Entrevista 09, militante urbano, 26 de noviembre de 2017.

78 Entrevista 07, militante urbano, 23 de noviembre de 2017.

${ }^{79}$ Entrevista 03, excombatiente, 25 de octubre de 2017.
} 
Los miembros de las FARC-EP sentían como propias las narrativas musicales y visiones compartidas sobre la historia de la organización, sus líderes y las acciones militares que allí se enunciaban. Además, la música reflejaba la experiencia de lo que las personas vivían en la guerra, las motivaciones que los llevaron a vincularse y su proveniencia humilde y rural. Así lo afirmaba un excombatiente del Frente 15: "lo hacía a uno sentir y lo hacía reflexionar: ¿YY de dónde es que vengo? ¿qué era, qué son mis padres, a qué se dedican?" 80 . También enmarcaba el sistema de valores de la organización y sus combatientes: solidaridad, fraternidad, justicia social, igualdad y libertad según los entrevistados ${ }^{81}$. En últimas, la canción insurgente reafirmaba el sentido de pertenencia de los militantes hacia la organización y encauzaba el horizonte de sentido y de acción.

Uno de los hallazgos más importantes de esta investigación fue la capacidad de la música para conectar a las diferentes estructuras de las FARC-EP y sus miembros, militantes urbanos y combatientes que no se conocían pero que hacían parte de una misma comunidad imaginada: la comunidad fariana. Inclusive en momentos de extrema dificultad como lo es la experiencia de cárcel, los entrevistados escuchaban música fariana y recordaban que hacían parte de un gran colectivo de hombres y mujeres, que en el campo y en las ciudades continuaban trabajando por lograr los objetivos de la organización. Tal y como lo afirmaba un músico de la organización que estuvo recluido en la ciudad de Medellín: "el usted poder escuchar la música fariana y recordar que hay gente allá peleando afuera y que están en su misma organización. Recordar la historia y recordar que usted no está solo, sino que hay todo un conglomerado apostándole a esto. Eso es fundamental" 82

\section{Funciones hacia "afuera": música fariana y sociedad civil}

Durante el conflicto armado las FARC-EP establecieron variados tipos de relación con la sociedad civil. En algunas zonas su presencia fue disputada con otros actores armados legales e ilegales mientras que en otros territorios lograron consolidar gobiernos insurgentes, mediante los cuales participaban- a la vez que regulaban - la vida cotidiana de las comunidades ${ }^{83}$. Ya fuese por una estrategia de supervivencia, por coerción o por una verdadera credibilidad en el proyecto revolucionario que planteaba la guerrilla, lo cierto es que las FARC-EP construyeron legitimidad y apoyo de la población en muchas zonas del país. La literatura reciente se ha enfocado en observar esta relación en términos del dominio militar y prácticas de resistencia de las comunidades ${ }^{84}$, de la regulación de la justicia por parte de los insurgentes en espacios como las Juntas de Acción Comunal ${ }^{55} \mathrm{y}$ del desarrollo interno de normas que moderan la violencia hacia los civiles ${ }^{86}$. Proponemos entonces observar el papel que jugó la música en la relación guerrilla- población como una ventana para comprender otros elementos del trabajo político que la insurgencia desarrolló durante su periodo de actividad y que aún no han sido suficientemente estudiados.

\footnotetext{
80 Entrevista 14, excombatiente, 14 de febrero de 2018.

${ }^{81}$ Entrevista 06, militante urbano, 16 de noviembre de 2017.

82 Entrevista 05, músico, 5 de noviembre de 2017.

83 Mario Aguilera Peña, Contrapoder y justicia guerrillera: fragmentación politicay orden insurgente en Colombia, 1952-2003, Bogotá, Debate, 2014; CNMH, Guerrilla y población civil trayectoria de las FARC 1949-2013, Bogotá, Imprenta Nacional, 2013; Teófilo Vásquez, Territorios, conflictos armado y politica en el Caquetá: 1900 - 2010, Bogotá, Universidad de Los Andes, 2015.

84 Ana Arjona, "Civilian Resistance to Rebel Governance", en Rebel Governance in Civil War, ed. Ana Arjona, Nelson Kasfir, y Zachariah Mampilly (Cambridge: Cambridge University Press, 2015), 180-202, https://doi.org/10.1017/CBO9781316182468.009.

85 Juan Sebastián Urdaneta, "El campo jurídico de las FARC: aproximación a las prácticas de justicia guerrillera", Revista VIA IURIS 21, 2016; Juan Sebastián Urdaneta, "Justicia guerrillera en tiempos de negociación: funcionamiento y retos en el postacuerdo”, Análisis Político 30: 90, 2017, 25-44.

${ }^{86}$ Francisco Gutiérrez-Sanín y Elisabeth Jean Wood, "What Should We Mean by 'Pattern of Political Violence'? Repertoire, Targeting, Frequency, and Technique", Perspectives on Politics 15: 1, 2017, 20-41; Ben Oppenheim y Michael Weintraub, "Doctrine and violence: The impact of combatant training on civilian killings", Terrorism and Political Violence 29: 6, 2017, $1126-48$.
} 
Un análisis superficial podría observar el lugar de la música fariana solamente como un elemento de propaganda del grupo armado hacia la sociedad civil, en el marco de lo que las FARC-EP denominaban "trabajo de masas". Sin embargo, los testimonios recogidos en esta investigación nos permiten afirmar que este papel fue mucho más profundo: la música permitió amenizar fiestas, llevar oferta cultural, conectarse con los modos de ser campesinos de las regiones y mostrarle a la población un lado más amable del proyecto político-militar. En últimas, la música sirvió para sumar solidaridades de las sociedades en las cuales la guerrilla hizo presencia.

Empecemos por el nivel de música como estrategia de propaganda. Los guerrilleros que mejor desempeño mostraban en lo político y cultural eran los seleccionados para el trabajo político de masas. Por cada frente se configuraban comisiones de organización con los mejores hombres y mujeres para realizar diversos trabajos con la sociedad. Una de las principales actividades que realizaban las comisiones eran las reuniones políticas. Con estas reuniones, las FARC-EP buscaban informar a la población de su programa revolucionario e incitar a la vinculación de personas a su organización, ya fuera como combatientes o como milicianos.

Siempre las reuniones políticas contaban con un "orden del día", previamente acordado por la comisión y el cual establecía los puntos a tratar. Era en este orden del día donde aparecía la música. Ya fuera para abrir o para clausurar la reunión, siempre se trataba de incluir un canto fariano, ejecutado en vivo por el guerrillero más destacado a nivel musical o por varios combatientes en coro: "Dentro de los compañeros que iban a hacer la reunión, ahí iba el famoso cantante. Entonces también elegían, bien sea lo hacían individual o lo hacían colectivo. Entonces si eran tres los que estaban haciendo la reunión entonces se ponían de acuerdo y todos tres cantaban. Y si no, uno solo" 87

Por supuesto, las canciones preferidas para estas reuniones eran aquellas que hacían referencia a la sociedad civil y la importancia de esta para la revolución y la lucha guerrillera. Entre las canciones más utilizadas para estas ocasiones, nuestros entrevistados recuerdan a "Canto a los niños" y "Campesino" de Lucas Iguarán. Esta última, narra la situación de precariedad que vive el campesinado colombiano por culpa del Estado y cómo la guerrilla se solidariza desde su lucha armada con las causas de esta población. De hecho, en una entrevista realizada por la emisora Cadena Radial Bolivariana "Voz de la Resistencia" (CRB) al propio cantautor en el año 2005, la misma guerrilla ya notaba la importancia de este tema en particular para el trabajo político de masas:

El tema Campesino Campesino se escucha mucho por las zonas rurales por donde se mueve la guerrilla. Las comisiones de guerrilleros que salen a hacer su trabajo organizativo en los poblados rurales suelen encontrarse con gente que hace sus fiestas y parrandas con la música guerrillera, y se escucha y se baila bastante esta canción 88

Aparte del canto en vivo durante las reuniones políticas, la guerrilla también desarrollaba otras estrategias de trabajo organizativo por medio de la música. Por ejemplo, los combatientes regalaban CDs tanto en estas reuniones como en diversos caseríos con apoyo del PC3. También buscaban sostener, si las condiciones lo permitían, la emisión continua de su emisora "Voz de la Resistencia" en pueblos y veredas, donde por supuesto la música fariana ocupaba un espacio importante en la parrilla de programación.

Del mismo modo, aunque de una forma más coercitiva, los combatientes asistían a tabernas y discotecas de las regiones para entregar el material sonoro, esperando que los dueños de estos establecimientos incluyeran la música insurgente en las listas de reproducción que circulaban mientras los clientes bebían licor y bailaban. Así lo afirmaba un excombatiente entrevistado, el cual desarrolló su actividad política en el departamento del Guaviare a principios de los años 2000:

${ }^{87}$ Entrevista 14, excombatiente, 14 de febrero de 2018

${ }^{88}$ CRB, 2007, op.cit. 
En esos ciclos de exploración colocábamos música, dejamos que la gente la escuche. Después ya pedimos que la coloquen y después ya es como el mandato, debe estar incluida dentro de un contexto de música: "usted coloca rancheras, Vicente Fernández, Darío Gómez, tangos...por favor, aquí también se debe de escuchar esta musiquita" 89

Nuestros entrevistados operaron en zonas rurales de Caquetá, Putumayo, Meta y Guaviare, donde la presencia sostenida le permitió generar a la insurgencia un trabajo más profundo con la música. En estos casos, el papel de esta fue mucho más allá que la mera propaganda. Al ser zonas alejadas de centros urbanos era las FARC-EP quienes llevaban la oferta cultural a estas regiones; regiones en donde el Estado aparte de no llegar con la oferta institucional de servicios básicos mucho menos lo hacía con el arte y la cultura.

Por ejemplo, las orquestas farianas eran las encargadas de amenizar las fiestas en los caseríos y poblaciones más apartadas de la geografía nacional. Los músicos más reconocidos, así como conjuntos vallenatos o de música popular insurgente, eran frecuentemente llevados por la organización a eventos de la población civil como cumpleaños y bazares, en donde además había peleas de gallos, reinados de belleza, partidos de fútbol y asados ${ }^{90}$. Orquestas como Los Rebeldes del Sur, por ejemplo, fueron claves durante la Zona de Distensión para animar las diferentes actividades en las que participaban guerrilla, gobierno, periodistas y pobladores del municipio de San Vicente del Caguán durante los diálogos de paz del año 1999-2002.

Es importante notar que parte del éxito de la música en vivo ejecutada por los músicos guerrilleros se debía a que en contextos rurales la transmisión oral se conectaba perfectamente con los modos de ser y la cultura popular de estas poblaciones. Esto, a su vez, se sincronizaba con la política institucional fariana de conectar a los combatientes con la riqueza del folklore en las regiones en donde operaban. Un ejemplo claro de esta situación la brindaba un músico fariano entrevistado:

Uno está dentro de la conferencia con los campesinos y ellos esperan un evento cultural. Más que cuando yo iba a dictar algún curso, llevaba la guitarra. Y claro, lo ven a uno y siempre le reclaman: ‘¿Usted acaso no trajo la guitarra?'... - 'No, no la traje'... - 'Ah bueno, pero nos dice una poesía'. Ellos estaban acostumbrados y por eso llevábamos a Horizonte, danzas u otra cosa ${ }^{91}$

Inclusive, en ocasiones la música también sirvió de medio para compartir momentos con músicos de la población civil que vivían en partes donde hacía presencia la guerrilla, tal y como lo afirmaba un músico de la organización: "Yo me iba con Pacho y nos mandaban para una comisión de finanzas, por allá en una vereda que sabíamos que había un viejito que es musico. Entonces nos íbamos para donde él, y vamos aquí a ensayar, a componer, a cantar. Y salía algo. Entonces uno caminando en esos territorios sabe quién le gusta ese tema del arte y la cultura92"

A diferencia del ejército revolucionario, en las ciudades el trabajo político del MB y el PC3 hacia la sociedad civil con la música fue mucho más complejo y solo se restringía a algunas acciones de propaganda armada o "tropeles". Los medios de circulación de esta música eran principalmente equipos de sonido ${ }^{93}$ y distribución de CDs en espacios sociales muy particulares, como las universidades públicas y algunas reuniones de militantes de izquierda no fariana (por ejemplo, las reuniones del PCC):

\footnotetext{
${ }^{89}$ Entrevista 10, excombatiente, 14 de enero de 2018.

${ }^{90}$ Entrevista 12, excombatiente, 5 de febrero de 2018

${ }^{91}$ Entrevista 02, músico, 29 de agosto de 2017

92 Entrevista 05, músico, 5 de noviembre de 2017

93 Por supuesto estas actividades requerían de un despliegue logístico importante y complejo para los militantes que operaban en la clandestinidad. Por tal motivo, era crucial el apoyo que simpatizantes de la causa podían brindar para que la realización de estos actos pudiese tener música fariana en equipos de sonido: "Imagínese usted andando por un sonido por ahí encapuchado,
} 
A veces éramos osados y los dejábamos en casas de la juventud, en eventos. Y se hacían cosas como repartir rápidamente. Digamos, un encuentro de juventud: se repartían veinte, treinta CDs sin hablar, Posiblemente terminarían en la basura, como puede que no. Terminaran en una colección de música. Así eran como las estrategias. No se hacía mucho, pero si se hacía ${ }^{94}$.

La restricción a estos espacios se debía, principalmente, a las difíciles condiciones de seguridad y la poca familiaridad de las audiencias con esta música, que a primera vista podía resultar muy impactante para los citadinos. A diferencia de las zonas rurales, en donde la guerrilla tenía una cierta trayectoria de reconocimiento y control sobre las áreas, los militantes urbanos no contaban con ninguna garantía para desarrollar su trabajo de masas. Por ejemplo, y según un músico entrevistado, hacer trabajo político en los barrios de Medellín con música fariana era imposible dada la presencia de grupos paramilitares en las comunas, los barrios de la ciudad e inclusive dentro de la universidad. Se prefería, entonces, recurrir a "sonidos conscientes" como el rap, el punk o el rock.

Pese a estas dificultades, los momentos en los que la militancia urbana pudo mostrar a la población su música se constituyeron en escenarios para mostrar otra cara del proyecto político, en donde "la revolución tiene que ser alegre, tiene que tener estos contenidos"95. Así lo afirmaba un militante urbano entrevistado:

Nos parece que la música genera un vínculo más del orden afectivo con las personas. Es decir, la música es una expresión del lado humano de este proyecto político, que la gente se diera cuenta de que no éramos terroristas, asesinos, sino que son personas que tienen ideas de transformación social y que en ese caso se vean reflejadas en la música. Era una forma más afable de expresar nuestras ideas o nuestras propuestas a la gente, en particular a los estudiantes de las universidades ${ }^{96}$

\section{Sonidos en transición: los usos de la música fariana hoy}

El acuerdo de paz y la transformación de las FARC-EP en el partido Fuerza Alternativa Revolucionaria del Común (FARC) ha traído consigo una transformación importante de las prácticas artísticas y musicales de las FARC, así como también de los espacios de escucha. Las diversas estructuras militares y políticas se fusionaron en el partido y ahora militantes urbanos y combatientes tienen la oportunidad de conocerse y compartir las tareas de la nueva organización legal. Si bien no es nuestro objeto central y futuras investigaciones deberán ahondar más en este escenario, si creemos conveniente esbozar algunas funciones que ha adquirido la música fariana en tiempos de paz.

\section{Sonidos para el nuevo partido político}

En el caso de aquellos que se mantienen activos en el partido político, el papel de la música ha sido variado. El primero, y más obvio, su uso como herramienta de propaganda política nacional y regional para los ahora candidatos a Senado y Cámara en el contexto electoral de Congreso y Presidencia del año 2018. Las FARC han incursionado, así, en la composición de los llamados “jingles”, canciones cortas que circulan masivamente en redes sociales como Facebook y WhatsApp. Una de las más llamativas se realizó para promover la candidatura de los antiguos comandantes Iván Márquez, Fabián Ramírez y Ramiro Durán en el sur del país. A ritmo de vallenato, invitaba a apoyar en las urnas el proyecto político de la antigua guerrilla:

de donde lo saca, donde lo guarda, eso requería de todas maneras toda una red de apoyo si se quiere que le dejara el sonido en tal lugar, que después lo dejara en tal otro" (Entrevista 07, militante urbano, 23 de noviembre de 2017).

94 Entrevista 09, militante urbano, 26 de noviembre de 2017

95 Entrevista 07, militante urbano, 23 de noviembre de 2017

${ }^{96}$ Entrevista 06, militante urbano, 16 de noviembre de 2017 
Hoy la Fuerza Alternativa es un partido que avanza

que toda Colombia diga: ya llegó nuestra esperanza

Marcando la rosa roja, nuestro pueblo ganará

que salga a votar el Huila, Putumayo y Caquetá

De la misma manera, se han compuesto canciones de larga duración para impulsar el voto ciudadano a favor del "Partido de la Rosa". Cerca al cierre de las campañas políticas, los artistas farianos Martín Batalla y Manuel Garzón lanzaron la canción "A participar: vota FARC", la cual a partir de la fusión de sonidos urbanos con gaitas y tambores muestra a las FARC como una nueva alternativa política que combatirá la corrupción y trabajará por la paz y la reconciliación. Aunque ya no era posible hacer eventos en la plaza pública, la música siguió circulando como una herramienta efectiva de propaganda.

La segunda función que ha adquirido la música fariana en tiempos de paz sigue siendo el amenizar y divertir, propiciando el compartir colectivo ahora en nuevos escenarios físicos. La apertura de espacios en las grandes ciudades para su acción política ha traído consigo la posibilidad de organizar conciertos en diferentes bares y auditorios de la ciudad. Estos eventos que podríamos denominar las horas culturales citadinas - y a los que generalmente llegan excombatientes, antiguos militantes clandestinos y público general - por supuesto se han acompañado de largas jornadas musicales, ya sea en vivo o en cd, en donde los asistentes bailan, toman algunos tragos y departen hasta altas horas de la noche.

La escucha de estos sonidos, en el caso de las ciudades, ya no es restringida como en tiempos de guerra y todos los miembros de la organización por fin pueden cantar juntos los temas que durante la confrontación debían escuchar a bajo volumen y de manera privada ${ }^{97}$. Un momento particularmente impactante para el autor durante su proceso de observación participante ocurrió en un evento realizado en la ciudad de Bogotá durante el mes de diciembre de 2017. Cerca de la media noche, y después de una larga secuencia de música popular colombiana y música fariana, sonó el himno de las FARC-EP. Todos los asistentes que hacen parte del partido se pararon de sus mesas y juntos entonaron dicha canción. Entre abrazos, militantes urbanos y excombatientes reafirmaban, así, su compromiso de continuar con el proyecto revolucionario, ahora desde la legalidad.

Al igual que en las ciudades, los distintos Espacios Territoriales de Capacitación y Reincorporación (ETCR) donde las FARC desarrolla su proceso de reincorporación también se han convertido en importantes escenarios para la escucha de la música fariana. Al no existir restricciones de escucha como si las había en la guerra, los excombatientes acompañan sus labores cotidianas con esta música. Inclusive, algunos proyectos colectivos han girado en torno a ella, como es el caso del teatro que se construyó en el ETCR de Riosucio (Chocó) o la cantina de música fariana que se empezó a planear en el ETCR de Carrizal (Antioquia). Sin embargo, esta escucha está cargada en muchas ocasiones de nostalgia y sentimiento por un proyecto político que no pudo triunfar por vía de las armas. Así lo ha notado un excombatiente entrevistado, que ahora trabaja para la Agencia de Normalización y Reincorporación (ARN) en el ETCR de Riosucio:

En las residencias de excombatientes [se escucha] periódicamente Julián y Lucas. Y muy fuerte esa promesa de triunfo. Yo todo el tiempo la escucho y trato de entender qué quieren decir con eso. Pero entiendo que puede ser una forma de elaborar un duelo, dejar el arma, ya recoger el proyecto armado. Y entiendo que la escuchan con algo de rabia, como con algo de tusa, algo de tusa hay ahî

En los ETCR también se ha propiciado la emergencia de nuevos proyectos musicales y artísticos farianos, así como la consolidación de los más antiguos, que ahora sacan a relucir su talento a las

\footnotetext{
${ }_{97}$ Por ejemplo, las nuevas condiciones han permitido que en las reuniones del partido político se puede escuchar la música fariana, tal y como lo afirma un joven militante entrevistado: "estamos reunidos y cuando se hacen pausas o en los momentos de dispersión, de descanso entonces ahí si se pone la música” (Entrevista 06, militante urbano, 16 de noviembre de 2017).

${ }^{98}$ Entrevista 08, excombatiente, 25 de noviembre de 2017.
} 
comunidades aledañas de estos territorios y a la sociedad colombiana en general. Sin duda alguna uno de los procesos más llamativos en este sentido ha sido la participación de la orquesta Los Rebeldes del Sur en las fiestas de San Pedro, celebración tradicional que reúne todo tipo de expresiones folclóricas nacionales en la ciudad de Neiva, y también en el concierto de lanzamiento de su partido político en la ciudad de Bogotá, donde la asistencia del público fue notable (El Tiempo 2017; Pacifista 2017).

Pese a esto, la permanencia de las prácticas musicales insurgentes se ha visto en riesgo por el proceso mismo de implementación de los acuerdos y todas las dificultades para que los excombatientes logren su sustento económico. Algunas agrupaciones se han fragmentado o han tenido que parar su actividad, dado que los integrantes se han visto obligados a buscar trabajo en diversos territorios del país. Algunos músicos hoy hacen parte, por ejemplo, del equipo de escoltas de los actuales líderes del partido FARC y no han tenido la posibilidad de retomar sus prácticas artísticas ${ }^{99}$

\section{Sonidos para quienes desertaron de la organización}

Una de las posibilidades de nuestra muestra de entrevistados fue poder explorar si existía hoy alguna práctica relacionada con la escucha de música fariana por parte de aquellos que desertaron de la organización años atrás y entraron a la vida civil en el marco de la desmovilización individual. Los resultados son variados e interesantes.

Algunos de ellos no han vuelto a escuchar la música de la organización. De hecho, su contacto con la música fariana se volvió a dar cuando fueron invitados a colaborar con esta investigación. Las razones son variadas: unos no lo han hecho porque consideran que el acceso a las canciones es difícil mientras que otros deliberadamente querían olvidar su pasado y empezar una nueva vida. Al respecto de esto último se refería una mujer excombatiente que se desmovilizó en el 2009: "cuando uno sale de por allá dice: 'yo no quiero saber nada de lo pasado. Yo quiero que todo lo que venga a mi vida sea nuevo'. Entonces uno no quiere saber nada"100

Otro grupo de excombatientes afirmaron haber escuchado la música fariana después de su desmovilización para negociar su propio pasado en el grupo y la nueva identidad que habían adquirido luego de su deserción. En últimas, la música sirvió para reconciliarse con el ayer y emprender su nuevo camino sin olvidar a donde pertenecieron y los ideales que defendieron durante su militancia revolucionaria. Así lo recuerda un excombatiente que perteneció a la organización durante 18 años:

En ese proceso me tocó devolverme a reconstruir en la memoria esa vida. Y ahí a veces he escuchado alguna canción para entender esto, o sea, que yo dejé esa militancia. Yo dejé esa militancia, pero esa militancia no me dejó a mí del todo. Y muchas de las cosas que yo soy yo las aprendí allá. Buenas y no tan buenas. Entonces esa música me ha servido para decir 'bueno, bien, ok. Yo soy otra cosa, pero también soy parte de estas cosas que están aquí en esa música’101

Un último grupo lo constituyen aquellos excombatientes para quienes las canciones farianas aún hacen parte de su cotidianidad musical. Quizás son los más nostálgicos, los que tuvieron buenas experiencias en su paso por la organización (Nussio 2012). Esta escucha de sonidos conocidos, familiares, los conecta con lo que fue su "hogar" por muchos años (Rosenthal 2001, 19). Al recordar con gratitud su pasado en la guerrilla, la música se convierte en un vehículo que los vuelve a sintonizar con esas experiencias pasadas e, incluso, mantiene el lazo ideológico con las FARC así ya no hagan parte de ellas (Ugarriza y Craig, 2012).

\footnotetext{
${ }^{99}$ Estas afirmaciones las hizo el músico fariano Martín Batalla en un evento académico, llevado a cabo en la Universidad de los Andes durante el mes de marzo de 2018.

100 Entrevista 03, excombatiente, 25 de octubre de 2017.

101 Entrevista 08, excombatiente, 25 de noviembre de 2017.
} 
Los medios de escucha de esta música son múltiples. Muchos de ellos lo hacen inclusive en los computadores de sus oficinas o tienen guardadas algunas canciones en sus celulares. Por ejemplo, un entrevistado afirmó que escucha con frecuencia el himno de las FARC en su puesto de trabajo: "Yo a veces lo escucho ahí en la oficina. Me pongo lo auriculares y lo pongo (...) Que día pasaron esos [personas] que hacían seguimiento a los que escuchaban mucho. Yo dije: 'ni modo, entonces ya estoy echado', porque ¿qué malo tiene escuchar esa música?’102

\section{Conclusiones}

Sin duda alguna, el universo de producción musical de las organizaciones armadas durante los conflictos supone un ejercicio desafiante, no solo por las preguntas que suscita sino también por las disciplinas y herramientas que se pueden acercar a él para analizarlo. En esta investigación hemos buscado comprender el papel que cumplió la música de las FARC-EP para la organización durante los años de confrontación armada. Aunque nos concentramos en el caso de la guerrilla colombiana, consideramos que los hallazgos aquí presentados pueden ser importantes para iluminar análisis posteriores sobre otros contextos en donde esté presente esta expresión artística y política por tres razones.

En primer lugar, ya que las funciones encontradas son igualmente importantes para cualquier organización armada: cohesionar ideológicamente a sus miembros, mantenerlos unidos socialmente y generar una identidad que los aglutine de manera sostenida. Con un estado actual de literatura que sigue haciendo énfasis en los mecanismos violentos por medio de los cuales los grupos armados socializan a sus combatientes con las normas y valores de la organización, este texto invita a pensar y analizar a profundidad otras formas no violentas por medio de las cuales se construyen comunidades armadas.

En el caso de las FARC-EP, la música fariana actuó como uno de los canales perfectos para socializar a sus miembros y generar en ellos emociones que los conectaran de manera profunda y duradera con su organización. Atendiendo las propiedades de la música para moralizar y el contenido ideologizado de sus letras, por medio del sonido insurgente la institución armada 'penetró la vida cotidiana de los combatientes' y 'conectó la experiencia individual con las metas y principios del grupo'103. Es decir, que la música fariana a la vez que proveyó un marco ideológico y de valores para afianzar la cohesión ideológica de los miembros de la organización (nivel semántico o de letras) también contribuyó al fortalecimiento de la cohesión social mediante la puesta en marcha de actividades colectivas como el baile (con música fariana de fondo), el canto propio y las propias de los artistas guerrilleros.

Una situación similar ocurre con el papel de la música hacia 'afuera', es decir hacia la sociedad civil. Los hallazgos aquí presentados también invitan a considerar la música como una parte importante del trabajo político de las agrupaciones armadas con la población, el cual no se agota en un ejercicio de propaganda. El sonido fariano, en el caso colombiano, conectó con los modos de ser de los campesinos y con las costumbres de las sociedades regionales a la vez que permitió llevar la oferta cultural a lugares en donde el estado colombiano no lo hacía. De esta manera, creo o consolidó lazos que le permitieron a la organización sumar simpatías y solidaridades con su causa revolucionaria.

Finalmente, porque la inserción de la música no ocurre en el vacío, sino en un momento histórico particular de la organización y su desarrollo militar y político, lo cual llama la atención sobre la necesidad de situar la producción musical de las agrupaciones armadas en un mapa más amplio de su trayectoria y del contexto regional y nacional. En el caso de las FARC-EP, esta ocurre en una coyuntura específica en donde la organización crecía de manera acelerada, estaba en una búsqueda de expansión territorial y necesitaba consolidar referentes identitarios latinoamericanos y nacionales luego de la crisis del socialismo internacional.

102 Entrevista 12, excombatiente, 5 de febrero de 2018.

${ }^{103}$ Livia Isabella Schubiger and Matthew Zelina, "Ideology in Armed Groups", PS: Political Science \& Politics, 50: 4, $2017,48-52$. 
¿Cómo se transformarán las funciones de las corcheas insurgentes en el largo camino hacia la consolidación de la paz en Colombia? La importancia que sigue teniendo hoy la música fariana es, en sí misma, una invitación para descubrirlo.

\section{Bibliografía}

\section{Fuentes impresas}

Aguilera Mario, Contrapoder y justicia guerrillera: fragmentación politica y orden insurgente en Colombia, 1952-2003, Bogotá, Debate, 2014.

Allen Lara, "Music and Politics in Africa", Social Dynamics 30:2, 2008, 1-19.

Almeida Paul y Urbizagastegui Ruben, "Cutumay Camones: Popular Music in El Salvador's National Liberation Movement", Latin American Perspectives 26:2, 1999, 13-42.

Arjona Ana, "Civilian Resistance to Rebel Governance", en Rebel Governance in Civil War, ed. Ana Arjona, Nelson Kasfir, y Zachariah Mampilly (Cambridge: Cambridge University Press, 2015), 180-202, https://doi.org/10.1017/CBO9781316182468.009.

Beltrán Miguel, Las FARC-EP (1950-2015): luchas de ira y esperanza, Bogotá, Ediciones Desde Abajo, 2015. Bolívar Ingrid, "Unheard Claims, Well-Known Rhythms: The Musical Guerrilla FARC-EP (1988-2010)", Andrea Fanta, Alejandro Herrero-Olaizola, y Chloe Rutter-Jensen (eds.), Territories of conflict: traversing Colombia through cultural studies, Rochester, University of Rochester Press, 2017, $209-220$.

Brader Ted, "Striking a Responsive Chord: How Political Ads Motivate and Persuade Voters by Appealing to Emotions", American Journal of Political Science 49:2, 2005, 388-405.

CNMH, Guerrilla y población civil trayectoria de las FARC 1949-2013, Bogotá, Imprenta Nacional, 2013.

Cohen Dara Kay, "The Ties That Bind: How Armed Groups Use Violence to Socialize Fighters", Journal of Peace Research 54:5, 2017, 701-14.

Corte Ugo y Edwards Bob, "White Power Music and the Mobilization of Racist Social Movements", Music and Arts in Action 1:1, 2008, 4-20.

Cortina Eudald, "Comunicación insurgente en América Latina: un balance historiográfico y una propuesta metodológica para su estudio", Izquierdas 41, 2018, 4-43.

Courtney Blankenship y Stan Renard, "Pop songs on political platforms", Journal of Popular Music Studies 29:3, 2017.

Currie James, Music and Politics, Routledge Handbooks Online, 2011.

Deaville James [et al.], "Making sense of 2016: Perspectives on popular music and the presidential campaigns", Journal of Popular Music Studies 29:3, 2017.

Eyerman Ron, "Music in Movement: Cultural Politics and Old and New Social Movements", Qualitative Sociology 25:3, 2002, 443-58.

Ferro Juan y Uribe Graciela, El orden de la guerra: las FARC-EP, entre la organización y la política, Bogotá, Pontificia Universidad Javeriana, 2002, 44.

Gal Reuven, "Unit Morale: From a Theoretical Puzzle to an Empirical Illustration-An Israeli Example", Journal of Applied Social Psychology 16:6, 1986, 549-64.

García-Guiu Carlos, "Cohesión grupal y espíritu de cuerpo en las unidades de Seguridad y Defensa", Revista de Pensamiento Estratégico y Seguridad CISDE 2:1, 2017, 65-77.

Gilman Lisa, My Music, My War: The Listening Habits of U.S. Troops in Iraq and Afghanistan, Wesleyan University Press, 2016.

González Aurelio, "Caracterización de los héroes en los corridos mexicanos", Caravelle 72, 1999, 83-97. Green Andrew, "Producing an Other Nation: Autogestión, Zapatismo, and Tradition in Home Studio Music-Making in Mexico City", Popular Music and Society, 2017, 1-20. 
Green Andrew, "Rage Against The Machine, Zapatismo, and the Aesthetics of Anger", Popular Music 34:3, 2015, 390-407.

Gutiérrez-Sanín Francisco y Wood Elisabeth Jean, "What Should We Mean by 'Pattern of Political Violence'? Repertoire, Targeting, Frequency, and Technique", Perspectives on Politics 15: 1, 2017, 20-41.

Héau Lambert Catalina y Giménez Gilberto, "El cancionero insurgente del movimiento zapatista en Chiapas. Ensayo de análisis sociocrítico", Revista Mexicana de Sociología 59:4,1997, $221-44$.

Herrera Ortega Silvia, "Un acercamiento al estudio y análisis de la relación música-política", Revista Folios 23, 2011.

Hutnyk John y Sharma Sanjay, "Music \& Politics: An Introduction”, Theory, Culture \& Society 17:3, 2000, $55-63$.

Jowell Marco, "Cohesion through socialization: liberation, tradition and modernity in the forging of the Rwanda Defence Force (RDF)", Journal of Eastern African Studies 8: 2, 2014, 278-93.

Katz-Rosene Joshua, From Protest Song to Social Song: Music and Politics in Colombia, 1966-2016", Tesis doctoral, CUNY, 2017.

Kirkegaard Annemette y Otterbeck Jonas, "Introduction: Researching Popular Music Censorship", Popular Music and Society 40: 3, 2017, 257-260.

Mampilly Zachariah, "Performing the Nation-State: Rebel Groups and Symbolic Sovereignty", Ana Arjona, Nelson Kasfir y Zachariah Mampilly (eds.), Rebel Governance in Civil War, Cambridge, Cambridge University Press, 2015, 74-97.

Manning Frederick, "Morale and cohesion in military psychiatry", Franklin Jones, Military Psychiatry: Preparing in Peace for War, Department of the Army, 1994, 1-18.

Manuel Peter, "World Music and Activism Since the End of History [sic]", Music and Politics 11:1, 2017.

Medina Carlos, FARC-EP: notas para una historia política, 1958-2008, Bogotá, Universidad Nacional de Colombia, 2009.

Nussio Enzo, "Ex-combatants and violence in Colombia: are yesterday's villains today's principal threat?" Third World Thematics: A TWQ Journal 3:1, 2017, 1-18.

Nuxoll Cornelia, "We Listened to it Because of the Message': Juvenile RUF Combatants and the Role of Music in the Sierra Leone Civil War", Music and Politics 9:1, 2015.

Oppenheim Ben y Weintraub Michael, "Doctrine and violence: The impact of combatant training on civilian killings", Terrorism and Political Violence 29: 6, 2017, 1126-48.

Osiebe Garhe, "The opportunism of political music culture in democratic Nigeria", Journal of African Cultural Studies 28: 1, 2016, 13-27.

Parra Max, "Pancho Villa y el corrido de la revolución", Caravelle 88, 2007, 139-49.

Pieslak Jonathan, "Sound Targets: Music and the War in Iraq", Journal of Musicological Research 26:2-3, 2007, 123-49.

Pieslak Jonathan, Radicalism and Music: An Introduction to the Music Cultures of Al-Qa'ida, Racist Skinheads, Christian-Affiliated Radicals, and Eco-Animal Rights Militants, Connecticut, Wesleyan University, 2015.

Pieslak Jonathan, Sound Targets: American Soldiers and Music in the Iraq War, Bloomington, Indiana University Press, 2009.

Pring-Mill Robert, “The Roles of Revolutionary Song - a Nicaraguan Assessment”, Popular Music 6:2, 1987, 179-89.

Reuben Federico, "Imaginary Musical Radicalism and the Entanglement of Music and Emancipatory Politics", Contemporary Music Review 34:2-3, 2015, 232-46.

Rosenthal Rob, "Serving the movement: The role(s) of music", Popular Music and Society 25:3-4, 2001, 1124.

Samacá Gabriel, Versos de amores que matan los odios malditos del yanqui opresor: música insurgente y discurso político de las FARC-EP”, Anuario Colombiano de Historia Social y de la Cultura 44:2, 2017, $227-$ 59 . 
Schubiger Livia y Zelina Matthew, "Ideology in Armed Groups", PS: Political Science \& Politics, 50: 4, 2017, 48-52.

Señorán Matías, The Role of Nicaraguan Protest Music in the Insurrection of 1979, Tesis de maestría, Warwick University, 2015.

Siebold Guy L, "The Essence of Military Group Cohesion", Armed Forces \& Society 33:2, 2007, $286-95$.

Street John, "Fight the Power': The Politics of Music and the Music of Politics", Government and Opposition 38:1, 2003, 113-30.

Street John, "Bob, Bono and Tony B: The Popular Artist as Politician", Media, Culture \& Society 24:3, 2002, 433-41.

Street John, Music and Politics, Cambridge, Polity Press, 2012.

Ugarriza Juan y Craig Matthew, "The Relevance of Ideology to Contemporary Armed Conflicts: A Quantitative Analysis of Former Combatants in Colombia", Journal of Conflict Resolution 57: 3, 2013, 44577.

Ugarriza Juan y Pabón Nathalie, Militares y Guerrillas: La memoria bistórica del conflicto armado en Colombia desde los archivos militares 1958 - 2016, Bogotá, Universidad del Rosario, 2017.

Urdaneta Juan, "El campo jurídico de las FARC: aproximación a las prácticas de justicia guerrillera", Revista VIA IURIS 21, 2016.

Urdaneta Juan, "Justicia guerrillera en tiempos de negociación: funcionamiento y retos en el postacuerdo", Análisis Político 30: 90, 2017, 25-44.

Vásquez Teófilo, Territorios, conflictos armado y política en el Caquetá: 1900 - 2010, Bogotá, Universidad de Los Andes, 2015.

Vego Milan, Operational W arfare at Sea: Theory and Practice, Taylor \& Francis, 2017, 244.

Villanueva Orlando, Canciones de la guerra: la insurrección llanera cantada y declamada, Bogotá, Universidad Distrital Francisco José de Caldas, 2016.

\section{Fuentes electrónicas y digitales}

Colprensa, "Farc, de la guerra al arte en el Putumayo", La Opinión, 12 de febrero de 2017. Disponible en: https://www.laopinion.com.co/colombia/farc-de-la-guerra-al-arte-en-el-putumayo-127883

Compañero nuevo FARC-EP, 2011, https://www.youtube.com/watch?v=M58C1YOzo2Y

CRB, Entrevista al Cantautor Guerrillero Lucas Iguarán. - FARC-EP Bloque Martín Caballero, 2007. Disponible en: https://resistencia-colombia.org/medios/crb/1098-entrevista-al-cantautor-guerrillero-lucas-iguaran

FARC-EP, Conclusiones de educación de la Séptima Conferencia Nacional de las FARC-EP, 1982. Disponible en: http://www.farc-ep.co/septima-conferencia/conclusiones-de-educacion-de-la-septima-conferencia-

nacional-de-las-farc-ep.html

FARC-EP, Estatuto de las Fuerzas Armadas Revolucionarias de Colombia - Ejército del Pueblo - (FARC-EP)", 1982. Disponible en: http://www.farc-ep.co/octava-conferencia/estatuto-farc-ep.html

FARC-EP, Octava Conferencia Nacional de Guerrilleros: conclusiones generales, 1993. Disponible en: http://www.farc-ep.co/octava-conferencia/octava-conferencia-nacional-de-guerrilleros.html

FARC-EP, Plan cisne 3 para 21 días, del 4 al 25 de agosto de 1980, 1980. Disponible en: http://www.farcep.co/septima-conferencia/ plan-cisne-3-para-21-dias-del-4-al-25-de-agosto-de-1980.html

Los Compañeros de las FARC-EP - La Guaneña, 2012, https://www.youtube.com/watch?v=fIZY9FTKctc Movimiento Bolivariano, Para el camarada cantautor del pueblo colombiano, Julián Conrado - FARC-EP Bloque Martin Caballero, 2013. Disponible en: https://resistencia-colombia.org/movimiento- 
fariano/movimiento-bolivariano/comunicados/1162-para-el-camarada-cantautor-del-pueblocolombiano-julian-conrado

\section{Entrevistas}

Entrevista 01, músico, 20 de septiembre de 2016.

Entrevista 02, músico, 29 de agosto de 2017.

Entrevista 03, excombatiente, 25 de octubre de 2017.

Entrevista 04, excombatiente, 26 de octubre de 2017.

Entrevista 05, músico, 5 de noviembre de 2017.

Entrevista 06, militante urbano, 16 de noviembre de 2017.

Entrevista 07, militante urbano, 23 de noviembre de 2017.

Entrevista 08, excombatiente, 25 de noviembre de 2017.

Entrevista 09, militante urbano, 26 de noviembre de 2017.

Entrevista 10, excombatiente, 14 de enero de 2018.

Entrevista 11, excombatiente, 25 de enero de 2018.

Entrevista 12, excombatiente, 5 de febrero de 2018.

Entrevista 13, excombatiente, 11 de febrero de 2018.

Entrevista 14, excombatiente, 14 de febrero de 2018. 